\title{
Models for acne: A comprehensive study
}

\author{
Indu Lata Kanwar, Tanweer Haider, Anju Kumari, Sandeep Dubey, Priyanka Jain, \\ Vandana Soni*
}

Department of Pharmaceutical Sciences, Dr. Harisingh Gour University, Sagar, Madhya Pradesh, India.

\begin{abstract}
Summary Acne vulgaris (AV) is the familiar chronic skin ailment affecting most of the individuals. This multifarious, disease involves the bacterium gram-positive, anaerobic Propionibacterium acnes ( $P$. acnes) which resides on skin microflora, and participated in acne inflammation and acne lesions. The object of this review is to discuss presently available in vitro, ex vivo, and in vivo models to evaluate the cosmetic formulations that are developed for dealing and prevention of acne formation. These various available models offer new chances for further research on biologically active materials, drugs $\&$ pharmaceutical as well as cosmetics for acne treatment.
\end{abstract}

Keywords: Acne, Propionibacterium acnes, pilosebaceous unit, sebaceous gland, animal models

\section{Introduction}

Acne, a multifarious chronic inflammatory state, is said to be happening within a pilosebaceous unit (PSU) including hair, hair follicles, sebaceous gland (SG) of the skin, characterized by non-inflammatory lesionsblackheads, whiteheads and inflammatory lesionspapules, pustul, nobless, nodules, and cysts (1-3). Acne is associated mostly with $P$. acnes which produces inflammation via release of extracellular enzymatic products like proteases, lipases, and hyaluronidases. About $94-95 \%$ of the pubertal population, $20-40 \%$ of adults and $<25 \%$ of women suffered from acne. Even after 25 years of age, women can suffer from is termed as adult female acne (4-6). Primarily four causes are critically responsible for the growth of acne lesion as shown in Figure 1 (7).

Some other factors are also responsible either alone or in combination for the formation of acne such as heredity, hormones, diet, and other bacterial species. This is well known that there are more chances for the children to have acne if their parents had acne in their young age, some heredity characters and genes which carry the similar information from parents to children. In another case, the various sex hormones like estrogens, androgens and tyrosine kinase hormones, corticotropin-

\footnotetext{
*Address correspondence to:

Dr. Vandana Soni, Department of Pharmaceutical Sciences, Dr. Harisingh Gour University, Sagar, Madhya Pradesh-470003, India.

E-mail: drvandanasoni@gmail.com
}

releasing hormone, adrenocorticotropic hormone, glucocorticoid, and melanocortins are required to regulate SG activity. The androgen hormones produced during the adulthood activate the secretion of the oil glands and creates an obstacle in the pores resulting in the progression of blackhead and acne (8-10). In general, $\mathrm{SG}$ is major responsible part causing disease due to the existence of the enzyme necessary for the formation of various hormones, cytokines and unique lipid mixture of squalene, wax esters, triglycerides and sebum (by the holocrine process) (11-13). The structure of all SG found on different skin parts are similar but their nature and the regulation of secretions and secretory process are different $(14,15)$. The larger part of SG in hair-covered areas is connected with hair follicles are known as pilosebaceous (PS) glands. The SG of the mucosal margin and modified skin are sovereign of hair follicles (16). Excess sebum secretion, abnormal differentiation and desquamation (the shedding) of follicular keratinocyte are some other responsible factors for acne (17). The upsurge of the microcomedo as a result of free fatty acid production is primary lesion which has been further developed as inflammatory along with non-inflammatory lesions $(18,19)$. In other cases, the various species of bacteria $P$. acnes, Staphylococcus epidermidis (S. epidermidis), Staphylococcus aureus (S. aureus), Streptococcus agalactiae (S. agalactiae), Klebsiella pneumoniae (K. pneumoniae) etc. has also been for the hyperactivity of the SG and ultimately acne (20). P. acnes are the major causative bacteria which by stimulating androgen receptor to increase the androgen 


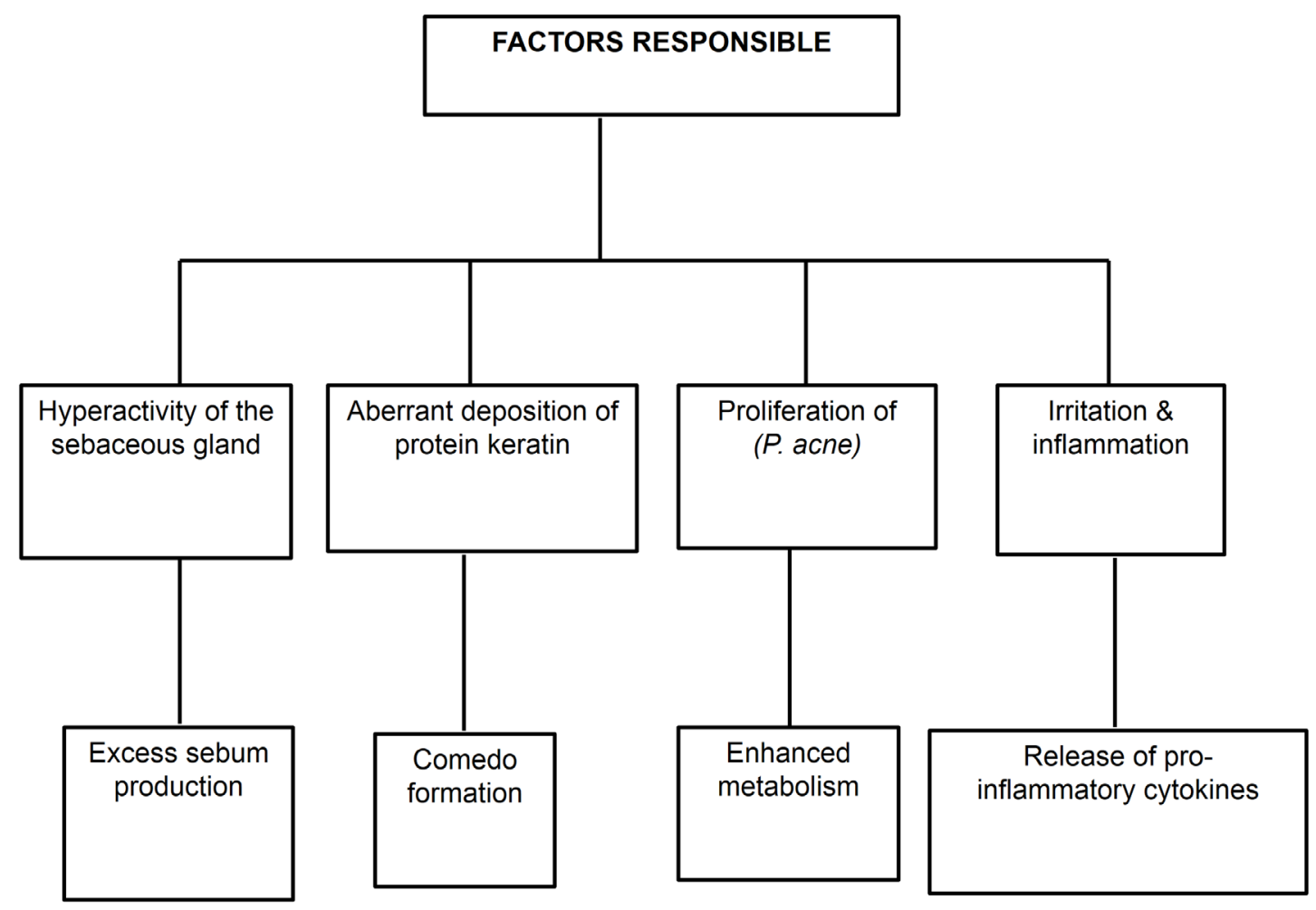

Figure 1. Factors responsible for acne.

secretion via androgenic hormone which induces the sebum production, keratinization, and colonization and finally induction of the inborn immune responses which cause inflammation (21-26). P. acnes also contribute to inflammation via activating various chemotactic factors and activate the inflammatory cascade through Toll-like receptors (27).

\section{Mechanism of acne formation}

The acne formation initiates with the overactive SG, follicular hyperkeratinization, immunological changes, and plugging of the infundibulum facilitating $P$. acnes, bacteria colonization, and inflammation (28). Increased sebum that is the major source of nutrients for $P$. acnes production is an important participating cause of the acne formation (29-31). The mechanism of acne formation should be understood for the design and estimation of the formulation for the effective treatment of acne. Hence, the detail pathogenic factors and process of acne formation is elucidated in Figure 2 and 3.

The various pathogenic factors blamed for the development of acne include the PSU, hyperkeratinization and undue sebum production, discharge inflammatory mediators, and inflammatory infiltrates (causes the progress of growing steps resulting in severity). P. acnes bacteria initiate the formation of propionic and acetic acid, thus resulting in the metabolism of sebaceous triglycerides into fatty acids. This results in the irritation of the follicular wall and surrounding dermis $(2,32)$. S. epidermidis, an anaerobic microorganism, is another causative microorganism involved in acne pathogenesis and produces fatty acid modifying enzyme that forms cholesterol by the fatty acid esterification in the skin $(33,34)$. S. Aureus, gram-positive rod-shaped bacteria, invade the skin and start producing extracellular enzymes such as lipases, proteases, hyaluronidases, and collagenase. These enzymes cause tissue injury and spread the pathogen into the deeper tissues $(35,36)$. $S$. agalactiae, gram-positive coccus bacteria, is also involved in the development of $P$. acnes. The capsular polysaccharides and the pore-forming toxins of $S$. agalactiae are the key factors of $S$. agalactiae (37). K. pneumoniae, gram-negative bacteria present on the skin flora, causes infection in acne patients undergoing longterm antibiotic therapy. The malicious factors of $K$. Pneumoniae is capsular polysaccharides, siderophores, and adhesins, this virulence produces seditious acne lesions papules, pustules (38).

Various models for the antiacne analyze of the drugs and drug carrier are available, but not a single article available which is fully devoted to models for antiacne activities (39). Therefore, with the present review article, the authors try to gather and compile the information regarding in vitro, ex vivo, and in vivo models applicable to study acne and are reviewed in the subsequent section (Figure 4).

\section{In vitro models for acne}

In vitro acne models used for the study are organ culture, monolayer culture, follicle model and testosterone- 


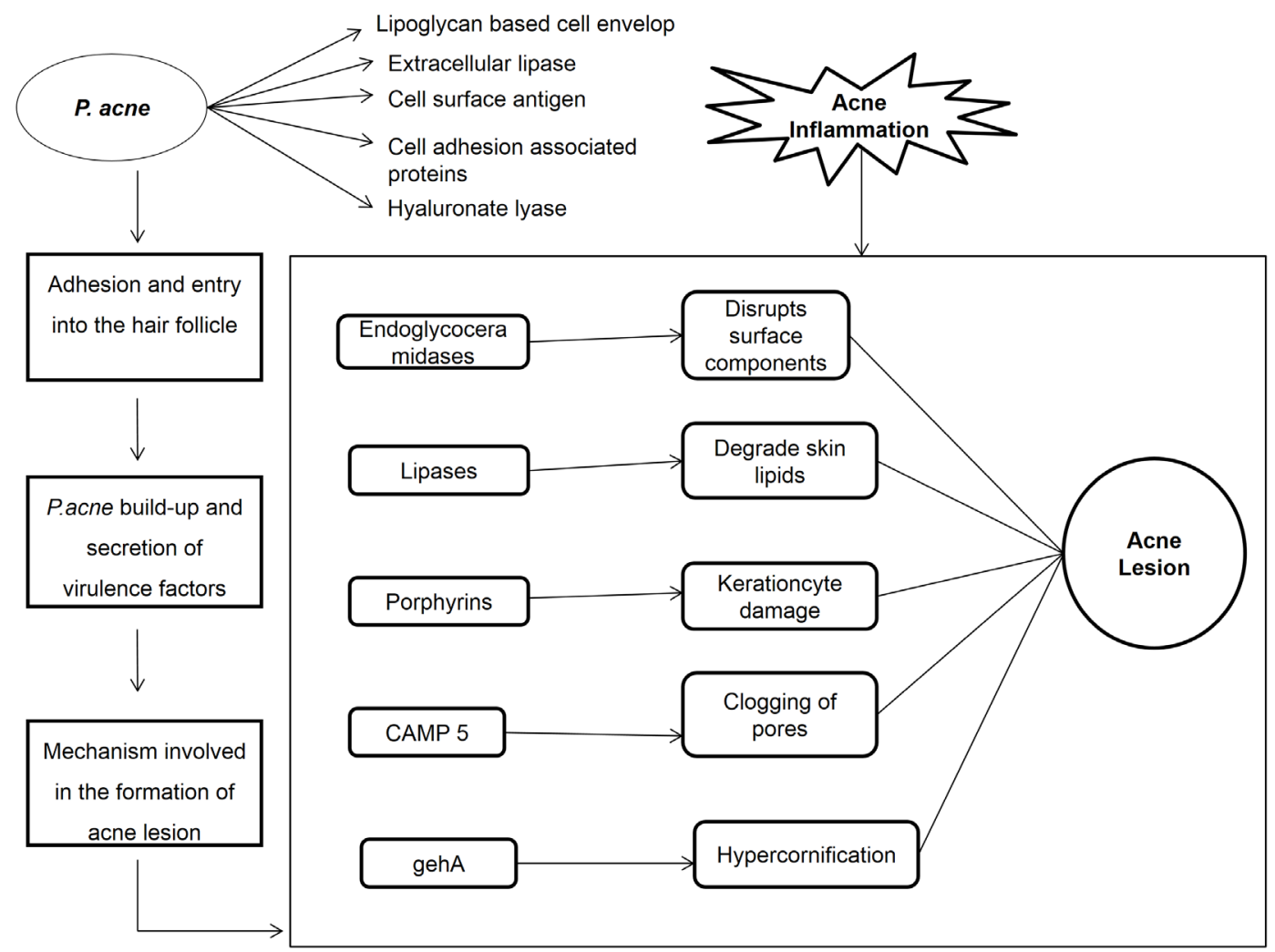

Figure 2. Mechanism of acne formation.

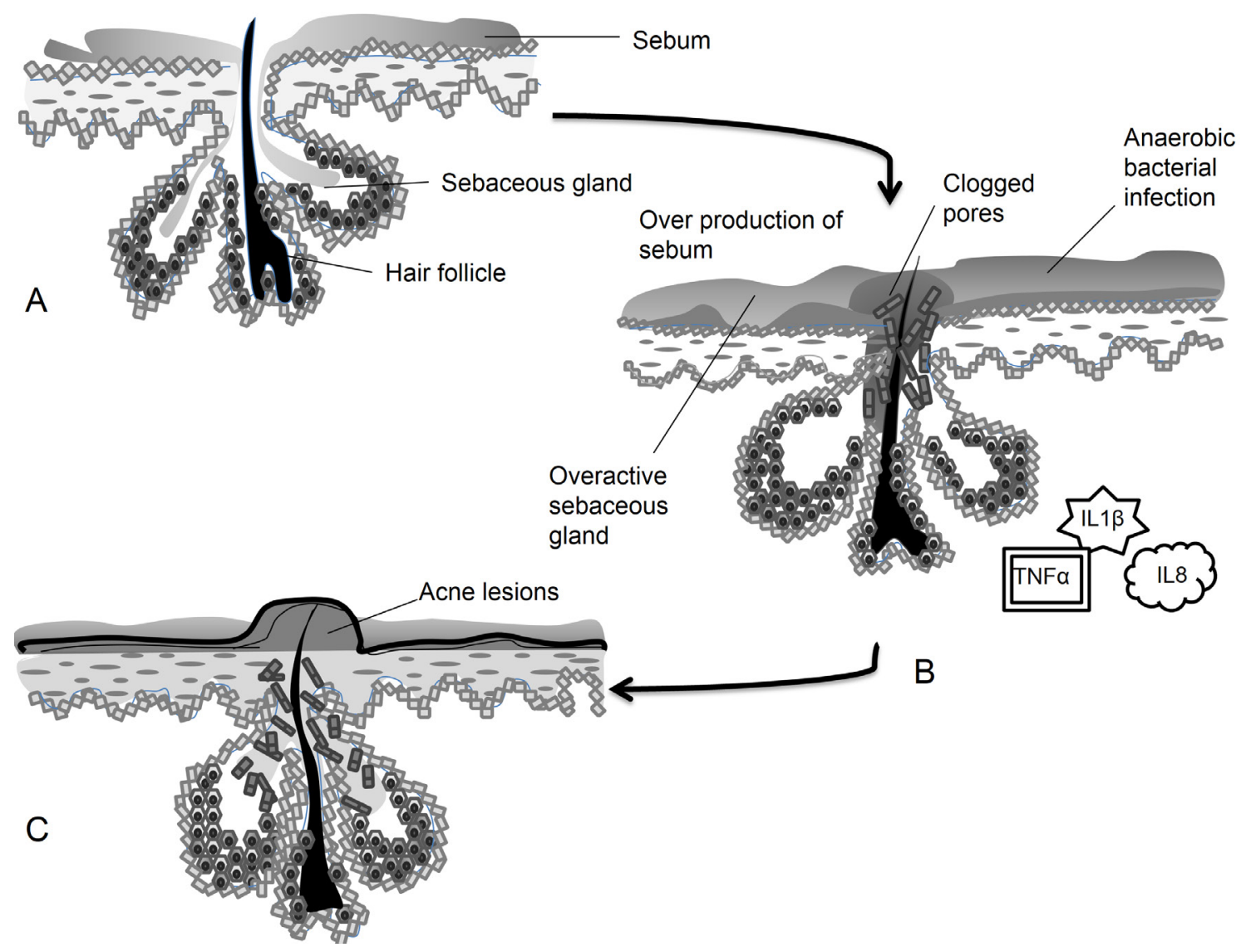

Figure 3. Causative pathogenic factors in acne: (1) Pilosebaceous unit. (2) Mechanism and effects of clogging pore. (3) Inflammatory infiltrates in acne formation. 


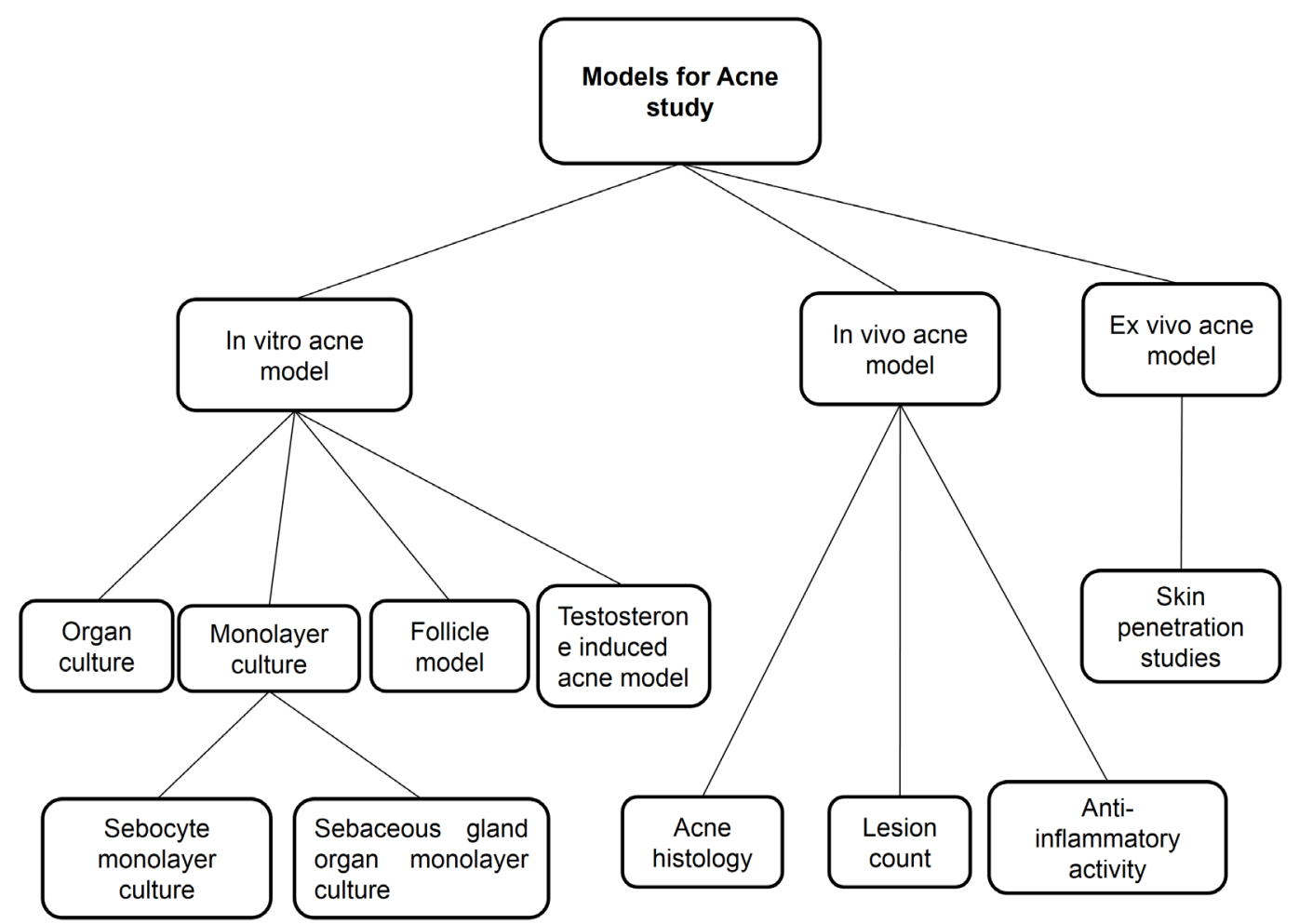

Figure 4. Models for acne study.

induced model. Though, no in vitro model is presented which can be used to study the complete perplexity of lesion formation. In in vitro organ culture model, the growth and preservation of any tissue, organ, and parts of organ allow the demarcation of that tissue and organ (40). In monolayer culture, cells are grown in a single layer on a culture medium in a Petri dish and prepared by the enzymatic separation of organ fragments. Cells in the monolayer culture need a substrate, which should be biologically inert, nontoxic and both the substrate and cells should be compatible with each other, otherwise, the culture will not endure and causes anomalous morphological changes (41). While in sebocytes (specialized epithelial cells) monolayer culture the sebocytes are used. These cells release their cellular content by degradation and by rupturing the cell membrane. The lipid synthesis in sebocytes is characterized by the rapid cell multiplication and differentiation of sebocytes. Cultured sebocytes are producing fewer amounts of wax esters and Squalene than the freshly isolated and in vivo SG (42).

\subsection{SG organ culture}

These models are important to explore the pathophysiology of human skin disorders which involves the SG, i.e. sebostasis, seborrhea, and acne. These models are a valuable means to develop and evaluate cosmetics and drug products. Human SG organ culture models highlight the role of SG and explain their functions in skin homeostasis. This model offers numerous benefits in comparison to sebocytes monolayer culture (40). These models are developed in isolation of SG by dissection of human skin (surgical waste, donor, cadaver, etc.) or by micro-dissection and shearing. The isolated specimens are transferred quickly into Dulbecco's modified Eagle's medium. The epidermal layers of the isolated specimen are separated and remaining dermis parts are directly placed in the growth medium. Intact SGs with/without dermal/epidermal components are utilized to measure lipogenesis rate in subjects with acne and the effect of substrates on lipid rates. To cultivate SG-derived cells, the isolated SGs were seeded in Petri dishes on a 3T3-cell feeder layer and complete culture medium. The cultures were incubated. The proliferation and lipid formation can be simultaneously examined in the basal and differentiated cell layer (43). An additional advantage lies over animal model in the fact that delivery of potential sebum suppression compound to the gland is not hindered, so absolute biological efficacy can be evaluated. The advantages of SG organ culture are distinct, although they involve the procedure which is time-consuming.

The SG in situ model is applicable for the antiacne studies using the culture of SGs isolated from animals. Toyoda and Morohashi performed organ culture on SG obtained from mice to compute the effects of neuropeptides (calcitonin gene-related peptide, substance $\mathrm{P}$, vasoactive intestinal polypeptide, and neuropeptide Y) along with nerve growth factor. SG treated with substance $\mathrm{P}$ resulted in the accelerated lipid synthesis over the control glands by escalating the rate of 
Table 1. Reported SG experimental models

\begin{tabular}{|c|c|}
\hline Experimental model & Ref. \\
\hline Isolation of SGs after enzymatic dissociation for the cultivation of human sebocytes (HSs). & 45 \\
\hline Introduced the condition to maintain SG ex vivo. & 46 \\
\hline $\begin{array}{l}\text { A modified version of the technique reported by Karasek, 1986. In this experiment the second } 0.4-\mathrm{mm} \text { dermal section is used as a } \\
\text { source of HSs after removal of epidermis and dermis layer (about } 0.4 \mathrm{~mm} \text { thick) of facial skin. }\end{array}$ & 47 \\
\hline $\begin{array}{l}\text { In vitro cultivation of human SG-derived cells. HS monolayer cultures as growth from the periphery of SG organ cultures were } \\
\text { obtained. }\end{array}$ & 48 \\
\hline $\begin{array}{l}\text { Xia et al. } 2009 \text { developed the } 1^{\circ} \text { sebocyte cultures by omitting the } 3 \mathrm{~T} 3 \text { fibroblast layer, and } 2^{\circ} \text { culture medium supplemented with } \\
\text { delipidized serum and serum-free keratinocyte basal medium. }\end{array}$ & 49 \\
\hline $\begin{array}{l}\text { Zouboulis et al. } 2009 \text { described the method for generation of an immortalized sebocyte cell line "SZ95" by transfecting human facial } \\
\text { sebocytes with Simian virus-40 large T antigen. This cell showed similar morphologic, phenotypic and functional characteristics } \\
\text { of normal HSs. Thiboutot et al. Immortalized human SG cell line (SEB-1) by applying the transfection system and Zouboulis et al. } \\
\text { immortalized SG cell line (Seb-E6E7) by the introduction of HPV16 E6 and E7 genes. }\end{array}$ & $50-52$ \\
\hline
\end{tabular}

differentiation and proliferation postulating that stress which leads to acne (44). SG experimental models are reported in Table 1.

\subsection{Sebocyte monolayer culture}

Although the advantages of SG organ culture are evident, the procedure is time-consuming and depends on continued sources of viable tissue for additional glands. Cell culture offers an alternative over organ culture maintenance, a massive amount of cells can be processed and frozen, allowing multiple experiments to be performed on a similar cell lineage. Several laboratories have productively cultured HS cultures, in the presence of fibroblast support and in serum-free medium. This allows observing the effects of serum and growth factors. HS culture is a well-formed model to change local environmental growth conditions, evaluate lipogenesis inhibitors in a higher throughput mode than that which would normally be obtained through the utilization of organ culture and facilitate the study of cell metabolism, specifically to the androgen metabolism and lipid synthesis. In sebocytes, the synthesis of lipid is dose-dependent (7). Sebocytes monolayer culture offers an advantage that maximum cells can be processed and frozen which is used for performing multiple experiments on a similar cell lineage. There are two procedures for generating sebocytes monolayer cultures: (a) first one is explant outgrowth method where isolated SG are attached to culture plates followed by addition of growth medium, following incubation for several days, visible outgrowths (proliferative basal sebocytes) are seen from the glands; (b) second one is SG digestion method which involves digestion of SGs by limited trypsin proteolysis and released cells are plated in mass culture upon a fibroblast feeder layer. After a few days, there is a replication of attached cells into small colonies that can be further used as cloned cells.

\subsubsection{Rat preputial sebocyte monolayer culture}

The preputial gland of rodent possibly is employed as a model for the human SG. These specialized glands open to the surface with a surface of the urethral meatus, and secretions are included in territorial marking and mating behavior. Rat preputial glands are utilized to produce monolayer cultures that can be isolated, digested, and cultured upon a fibroblast nutritive layer $(53,54)$. The preputial monolayer cultures of these cells are a suitable model for evaluating the hormone effects on sebaceous development and growth. The effects of estrogen on preputial cell behavior and determination of the cultured cells along with the action of androgen and effect of peroxisome proliferator-activated receptor (PPAR) has been reported $(55,56)$. Preputial cells differentiate in a similar process, but to an overall lesser extent than human sebocytes (57). Preputial cells cultured in vitro lack the existence of PPAR ligands that will induce the formation of the oily or lipid droplet (58).

\subsection{Follicle model}

The follicle model is used to appraise the context among sebocytes, keratinocytes and P. acnes. P. acnes colonizes on superficial skin and PSU. For determining the connection between sebocytes, keratinocytes and $P$. acnes, preserved sebocytes (SZ95) and keratinocytes (HPV-KER) were cultured in the same chamber which is divided by a permeable polyester membrane. The permeable polyester membrane avoids the dispersion of soluble molecules among the chambers. In the healthy PSU, P. acnes can only be found in the hair follicular cells (59).

\subsection{Squalene oxidation model}

Squalene oxidation models have been developed as the skin tissue engineering models for the in vitro testing of acne. These models are utilized for determining the sebum composition as well as the role of oxidative derivatives of squalene (60). These models are developed 
by the squalene oxidation under controlled atmosphere i.e., by oxygen, ultraviolet irradiation and controlled incubation at prescribed conditions. The oxidized squalene derivatives have been analyzed and measured by GCMS and NMR at the predecided condition. The reconstructed human epidermis (RHE) models are also developed which are depended on the use of oxidative derivatives of squalene. On this morphology of the RHE were studied and specific markers such as inflammatory cytokines were measured. This model is used to calculate the drug in vitro activity and their formulations to inhibit acne development (61).

\subsection{Testosterone-induced acne model (TIAM)}

Testosterone is, a steroidal hormone, accountable for different forms of acne. The conversion of testosterone to dihydrotestosterone, stimulate keratin through its follicular receptor (62). Both the dihydrotestosterone and testosterone are the causes of acne because of the increased activity and size of SG. The TIAM is prominent for determining the efficacy and biocompatibility of the various components (4) (Figure 5).

\section{In vivo models for acne}

These models have been utilized to predict the efficacy of the drug in the treatment of that particular disease (63). Recently, animal models have been used for drug development in an exponential manner. The invivo model has the same physiology as the events of human anagenesis and advantageous to appraise the anti-acnegenic nature of the formulation. These models imitate both human skin diseases and conditions. There are different human and animal models are available for acnegenesis, such as the Mexican hairless dog, rabbit ear assay and Rhino mouse model that closely resembles comedogenesis (64).

Skin irritation is the culmination of a complex inflammatory process involving epidermal keratinocytes, dermal fibroblasts, endothelial cells, and annexing leukocytes in which early symptoms may consist of swelling, redness, and itching continuing to scaling and erythema (7). Histologically, irritation involves both the epidermis and dermis with inflammatory infiltrates entering from the microvasculature and chemical mediators being released from the different types of cells. The important task of the keratinocytes is not only to provide a barrier and integral structure of the PS follicle but also to participate as the essential task in the inflammatory process through the release/response to surrounding cytokines. Alternatively, the incite inflammation is the key role of bacteria in acne. In vivo acne models allow studying and determining the lesion count, the effect of the drug on bacteria, comedogenicity, histology study, and other anti-acne activity.

Two types of inflammatory animal models used for

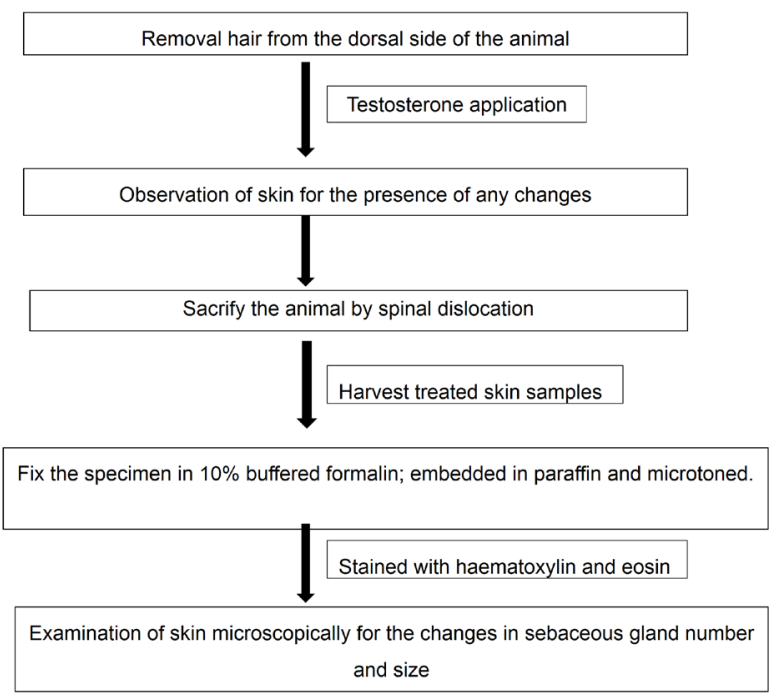

Figure 5. In-vitro testosterone acne induced model.

ascertaining the immunostimulatory, pathogenic and proinflammatory properties. These models included; 1) an acute inflammation model, induced by drug topically and 2) a chronic skin inflammation model partially relevant to $\mathrm{AV}$, which is developed with the bacterial intradermal injection into the mouse's ear. The detailed procedure for the estimation of anti-acne inflammatory activity and ear thickness as well as acne histology and lesion count shown in Figure 6 and 7, respectively (65-68).

Cytotoxins are compounds that stimulate chemotactic activity and are produced by $P$. acnes and other microorganisms in the follicle, which attract neutrophils (69). These chemical mediators can then go on to activate macrophages, neutrophils, natural killer cells and other cells inducing the production of additional cytokines. Major inflammation mediators include; histamine, leukotrienes, interleukins, prostaglandins, and neuropeptides. Neutrophils then produce enzymes and generate free oxygen radicals that will result in the disruption of the follicle. Inflamed parts such as pustules, papules, and nodules are developed when comedones rupture and their contents extruded into the dermis rather than above the skin surface. For analysis purposes, the live P. acnes (ATCC 6919) will be injected into the mouse's ear. The ear is then cut out on day 1 to day 5 after bacterial injection, and homogenized with the tissue grinder, in $0.9 \%$ saline solution. Then supernatant centrifuged for $10 \mathrm{~min}$ at $2000 \times \mathrm{g}$ to separate out the clear liquid and then cytokine is measured. The TNF- $\alpha$ and IL-1 $\beta$ concentrations are determined with the help of ELISA kits $(70,71)$.

\section{Skin penetration studies}

Ex vivo conditions permit examination on an organism's cells or tissues under more controlled conditions than is attainable in vivo testing, to the detriment of modifying the "natural" environment. These studies help to observe 


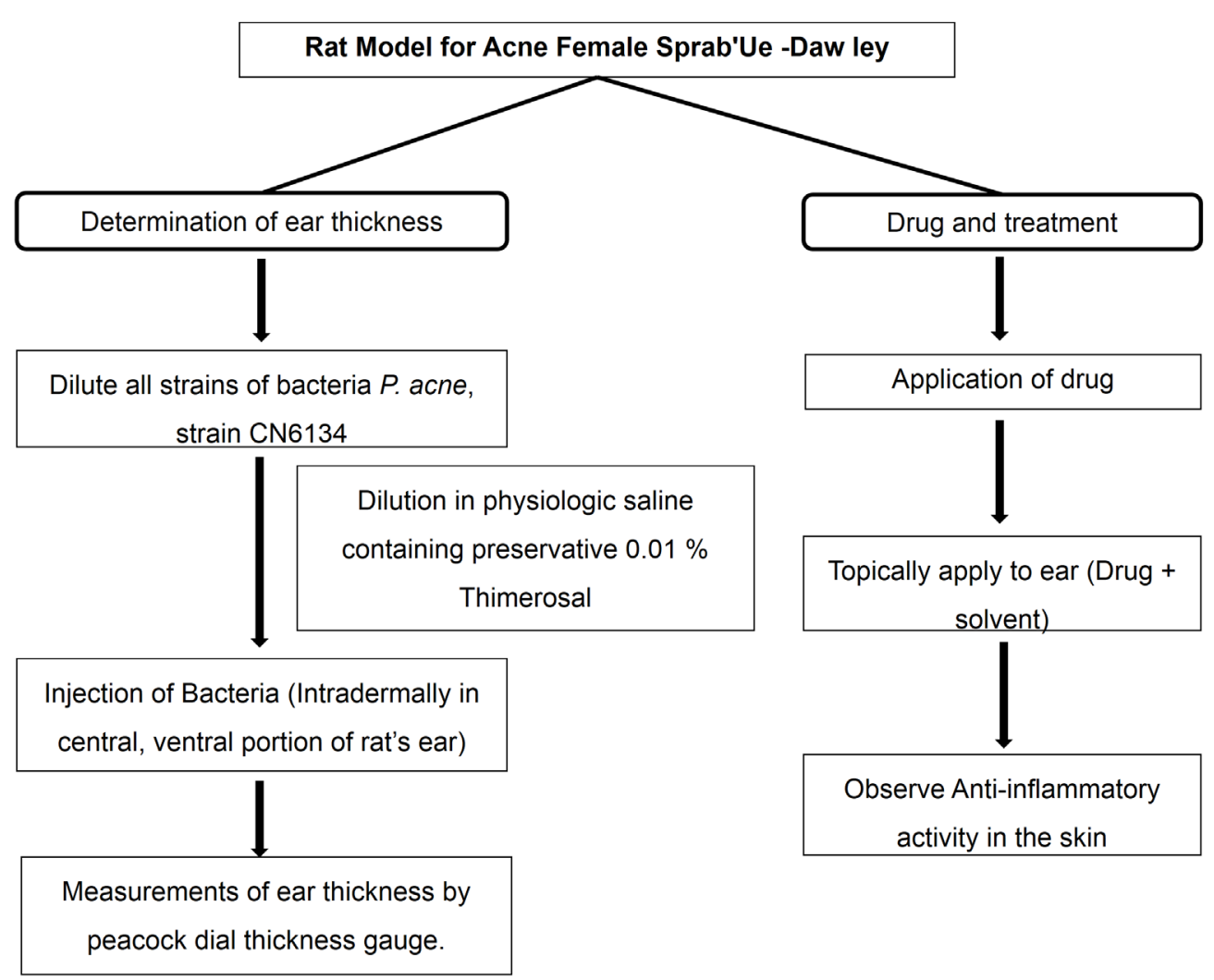

Figure 6. Rat model for acne for determination of anti-inflammatory activity and ear thickness.

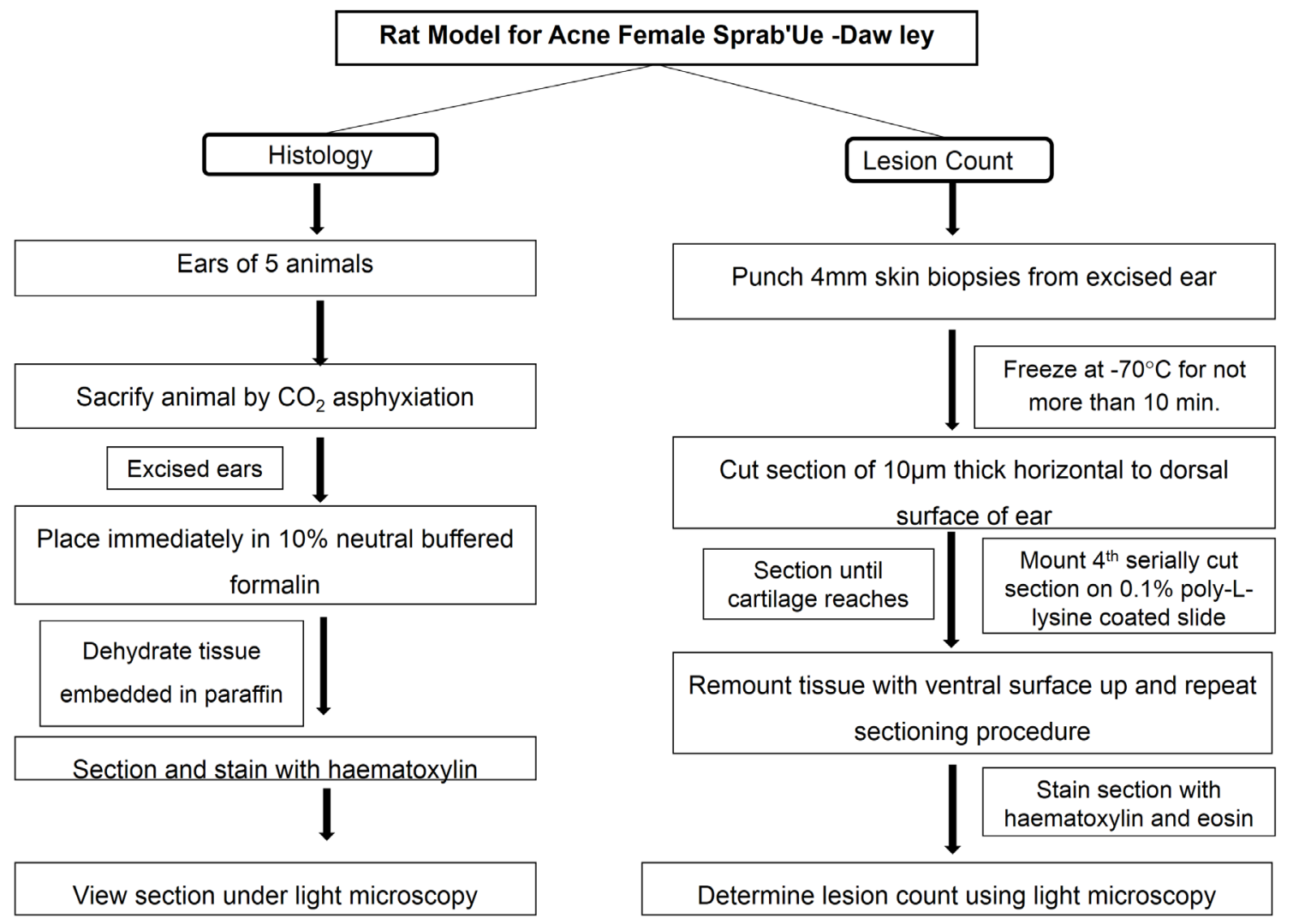

Figure 7. Rat Model for acne histology and lesion count. 
the permeation rate of specific compounds through the animal skin (72). Ex vivo models are economical, effortlessly obtained, but not suitable to determine the long-term experiments or the heat sink effect. The studies can be summarized with the help of Figure 8 . For in vitro permeation study, the permeation rate of the carrier through the skin, along with drug entrapped will determine by using egg membrane (Figure 9) (73).

\section{Estimation of antimicrobial (ATM) activity}

The activity of ATM component is measured by

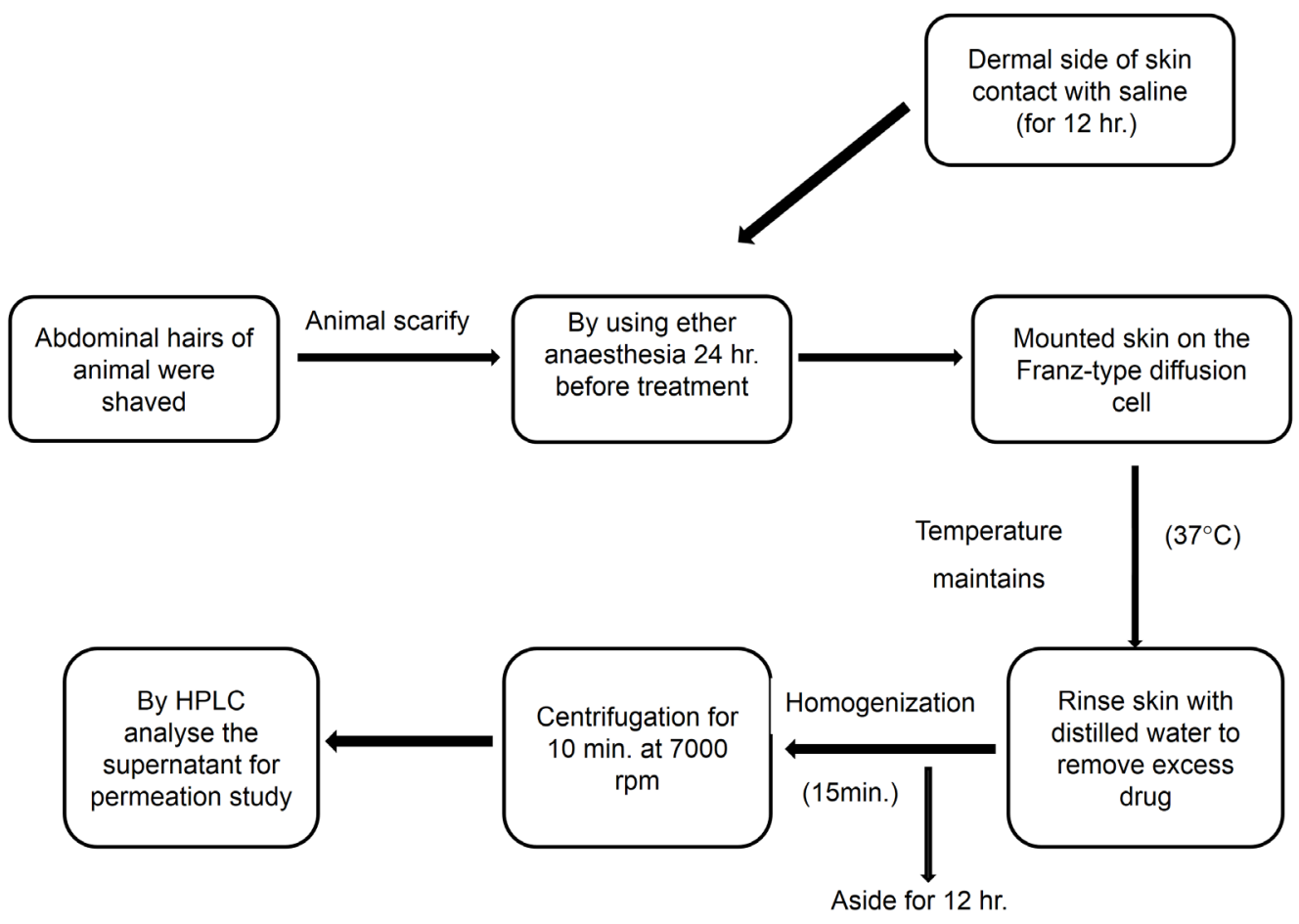

Figure 8. Ex-vivo skin penetration studies.

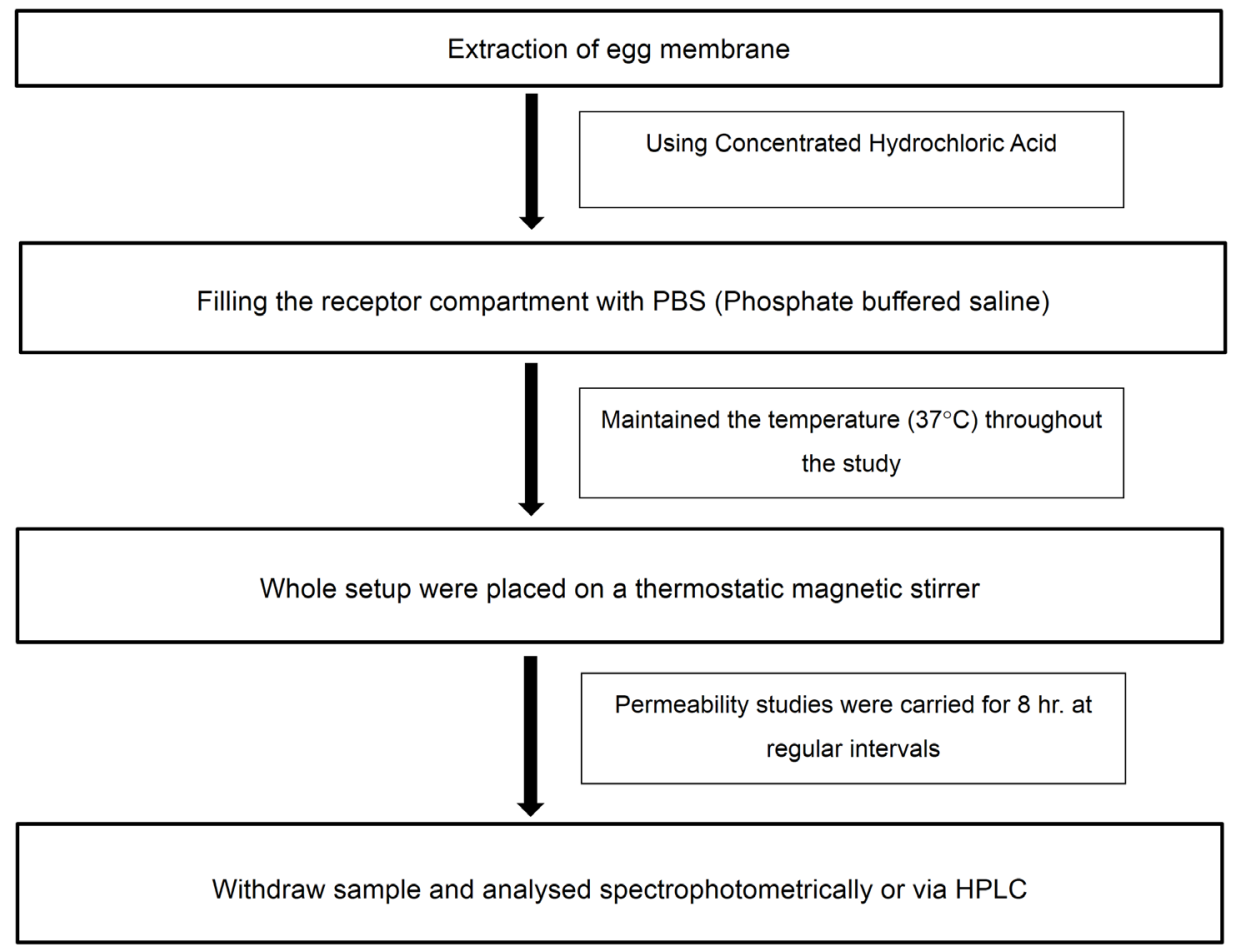

Figure 9. In-vitro model for skin permeation study using egg membrane. 
determining the minimum inhibitory concentration (MIC). The MIC is the smallest concentration of an ATM agent that will reduce the growth and development of a definite type of organism after sub-culture on antibioticfree medium. MIC is employed to confirm organism resistance and in vitro potency of the new ATMs and it is regarded as the 'gold standard' for the determination of susceptibility of the organism to ATMs. The methods used for determining the MIC of the therapeutic agent are discussed below $(4,74)$.

\subsection{ATM assay}

For ATM assay, two microbial varieties $S$. aureus (MTCC 96) and P. acnes (MTCC 1951) is usually used. The activities of compound and formulations have been evaluated against $P$. acnes in agar and $S$. aureus in pre-warmed agar plates (APLs). For this microbial cultures should preserve in their suitable agar slants at $4^{\circ} \mathrm{C}$. This is used as stock cultures (75). About $60 \mu \mathrm{L}$ of each component is placed on sterile paper discs $(8 \mathrm{~mm}$ diameter) kept above the APL surface. Plates were cultured at $37^{\circ} \mathrm{C}$ for $48 \mathrm{~h}$ (72). The ATM potential of the test compound is determined by the measurement of the zone of inhibition (ZOI) diameter $(2,76)$.

\subsection{Tube dilution technique (test tube method)}

The tube dilution method is referred to as the standard method for the assessment of microbial resistance against a specific ATM agent. In test tube method, antibiotic dilutions are prepared in a liquid medium. In the series of culture tube (filled with microbial growth medium) (67) the test compound (variation in concentrations of test compound) is added. Incubate the culture tube. If there is no turbidity found it represents inhibition in the tube $(7,77)$.

\subsection{Agar diffusion method}

It is applied for the assessment of the ATM MIC. Both the nutrient agar and nutrient broth medium have been used for the bacterial culture and for the assessment of ATM potency (78). To the Petri plates containing an agar medium, ATM agent is added to filter paper disc and places it in contact with the agar surface (46). During the incubation period, the ZOI will be formed, after the diffusion of the test compound onto the APL from the filter paper. The effectiveness of the therapeutic agent is determined by the diameter of ZOI $(5,47,75)$.

\subsection{Anti-androgen hypersecretion of sebum}

The fuzzy rat model is selected to study the assessment of hyperplastic SG and sebum hypersecretion. This model is a genetic mutant variety between hairy albino and hairless rats. It is used to determine the effects of molecules or drugs on the reduction of glandular and ductal hyperplasia in human acne. For this, a sample has been diminished into the appropriate vehicles (i.e. water, alcohol) etc. and applied on the back of all male rats for 2 months, except the control and the vehicle receiving groups of rats. The size of the sebaceous glandular lobes (GLs) and ducts will be quantified in both the fragmented epidermal preparations and frozen sections of skin. After 8 weeks it is evaluated by staining with osmium-potassium dichromate solution. The calculation can be done by the number of bromodeoxyuridine (BdU) positive cells in the GLs in split-skin tissues stained with BdU immunochemistry (48).

\subsection{Ex vivo pig skin colonization}

The segment of hair free pigskin has been sterilized in $70 \%$ alcohol were clipped and infect with bacterial or fungal inoculum. Then the skin pieces (10 per group) are treated with $100 \mu \mathrm{L}$ of ATM agent. The treated skin has been incubated for $24 \mathrm{~h}$ at $35 \pm 2^{\circ} \mathrm{C}$ under humidified conditions. Colonies were counted by swabbing the skin surface with a sterile cotton-tipped applicator soaked in $1 \mathrm{~mL}$ of sterile saline supplemented with ATM inhibitor. Then after the sampling solutions is diluted and poured into the plates for colony counts. If there were no viable colonies observed, this is assigned as low detection value $(49,79)$.

\section{Conclusion}

Recently, a remarkable headway has been attained in delineating the models available for the acne. In conclusion, the culture of the human SG cell model offers unique possibilities for further fascinating investigations into the role and importance of the $\mathrm{SG}$ in the acne development. Moreover, these models which are an adequate tool for evaluation of the pharmacological properties of new anti-acne compounds. The sebum model sustains $P$. acnes progresses and biofilm formation and mimics some important phases of the PSU. Multiple models are available for the identification of technologies for effective acne treatment. By using these models, it is possible to estimate the mechanism of action of lead compounds. More complex culture systems, including three-dimensional models, are under development. The above-discussed approaches are very useful in further advancement in the selection of efficacious drug to the development of drug delivery systems for the acne treatment.

\section{References}

1. Feuillolay C, Pecastaings S, Le Gac C, Fiorini-Puybaret C, Luc J, Joulia P, Roques C. A Myrtus communis extract enriched in myrtucummulones and ursolic acid 
reduces resistance of Propionibacterium acnes biofilms to antibiotics used in acne vulgaris. Phytomedicine. 2016; 23:307-315.

2. Han R, Blencke HM, Cheng H, Li C. The antimicrobial effect of CEN1HC-Br against Propionibacterium acnes and its therapeutic and anti-inflammatory effects on acne vulgaris. Peptides. 2018; 99:36-43.

3. Dessinioti C, Katsambas A. Difficult and rare forms of acne. Clin Dermatol. 2017; 35:138-146.

4. Raza K, Singh B, Singal P, Wadhwa S, Katare OP. Systematically optimized biocompatible isotretinoinloaded solid lipid nanoparticles (SLNs) for topical treatment of acne. Colloids Surf B. 2013; 105:67-74.

5. Maroñas-Jiménez L, Krakowski AC. Pediatric acne: Clinical patterns and pearls. Dermatol Clin. 2016; 34:195-202.

6. Di Landro A, Cazzaniga S, Cusano F, Bonci A, Carla C, Musumeci ML, Patrizi A, Bettoli V, Pezzarossa E, Caproni M, Fortina AB, Campione E, Ingordo V, Naldi L, Group for Epidemiologic Research in Dermatology Acne Study Group. Adult female acne and associated risk factors: Results of a multicenter case-control study in Italy. J Am Acad Dermatol. 2016; 75:1134-1141.

7. Bajor J. B18 In Vitro Models for the Evaluation of Antiacne Technologies. In: Acne and Its Therapy (Webster GF, Rawlings AV, eds.). CRC Press, 2007; pp. 275.

8. Thiboutot DM. Overview of acne and its treatment. Cutis. 2008; 81:3-7.

9. Arora MK, Yadav A, Saini V. Role of hormones in acne vulgaris. Clin Biochem. 2011; 44:1035-1040.

10. Melnik BC. Acne vulgaris: The metabolic syndrome of the pilosebaceous follicle. Clin Dermatol. 2018; 36:2940.

11. Miyake K, Ciletti N, Liao S, Rosenfield RL. Androgen receptor expression in the preputial gland and its sebocytes. J Invest Dermatol. 1994; 103:721-725.

12. Muise ES, Zhu Y, Verras A, Karanam BV, Gorski J, Weingarth D, Lin HV, Hwa J, Thompson JR, Hu G, Liu J, He S, DeVita RJ, Shen DM, Pinto S. Identification and characterization of sebaceous gland atrophy-sparing DGAT1 inhibitors. PLoS One. 2014; 9:e88908.

13. Hinde E, Haslam IS, Schneider MR, Langan EA, Kloepper JE, Schramm C, Zouboulis CC, Paus R. A practical guide for the study of human and murine sebaceous glands in situ. Exp Dermatol. 2013; 22:631637.

14. Tsatsou F, Zouboulis CC. Anatomy of the sebaceous gland. In: Pathogenesis and Treatment of Acne and Rosacea (Zouboulis C, Katsambas A, Kligman A, eds.). Springer, Berlin, Heidelberg, 2014; pp. 27-31.

15. Shi VY, Leo M, Hassoun L, Chahal DS, Maibach HI, Sivamani RK. Role of sebaceous glands in inflammatory dermatoses. J Am Acad Dermatol. 2015; 73:856-863.

16. Zouboulis CC, Makrantonaki E. The Role of the Sebaceous Gland. In: Pathogenesis and treatment of acne and rosacea (Zouboulis CC, Katsambas AD, Kligman AM, eds.). Springer, Berlin, Heidelberg, 2014; pp. 7790.

17. Jahns AC, Eilers H, Ganceviciene R, Alexeyev OA. Propionibacterium species and follicular keratinocyte activation in acneic and normal skin. Br J Dermatol. 2015; 172:981-987.

18. Davidovici BB, Wolf R. The role of diet in acne: Facts and controversies. Clin Dermatol. 2010; 28:12-16.
19. Adebamowo CA, Spiegelman D, Danby FW, Frazier AL, Willett WC, Holmes MD. High school dietary dairy intake and teenage acne. J Am Acad Dermatol. 2005; 52:207-214

20. Owen L, Grootveld M, Arroo R, Ruiz-Rodado V, Price P, Laird K. A multifactorial comparison of ternary combinations of essential oils in topical preparations to current antibiotic prescription therapies for the control of acne vulgaris-associated bacteria. Phytother Res. 2017; 31:410-417.

21. Charny JW, Choi JK, James WD. Spironolactone for the treatment of acne in women, a retrospective study of 110 patients. Int J Womens Dermatol. 2017; 3:111-115.

22. Azmahani A, Nakamura Y, McNamara KM, Sasano H. The role of androgen under normal and pathological conditions in sebaceous glands: The possibility of target therapy. Curr Mol Pharmacol. 2016; 9:311-319.

23. Dessinioti C, Katsambas A. Propionibacterium acnes and antimicrobial resistance in acne. Clin Dermatol. 2017; 35:163-167.

24. Tahir CM. Pathogenesis of acne vulgaris: Simplified. J Pak Assoc Dermatol. 2016; 20:93-97.

25. Rosenfield RL, Deplewski D. Role of androgens in the developmental biology of the pilosebaceous unit. Am J Med. 1995; 98:S80-S88.

26. Barrault C, Garnier J, Pedretti N, Cordier-Dirikoc S, Ratineau E, Deguercy A, Bernard FX. Androgens induce sebaceous differentiation in sebocyte cells expressing a stable functional androgen receptor. J Steroid Biochem Mol Biol. 2015; 152:34-44.

27. Zouboulis CC. Acne and sebaceous gland function. Clin Dermatol. 2004; 22:360-366.

28. Paithankar DY, Sakamoto FH, Farinelli WA, et al. Acne treatment based on selective photothermolysis of sebaceous follicles with topically delivered lightabsorbing gold microparticles. J Invest Dermatol. 2015; 135:1727-1734.

29. Bissonnette R, Poulin Y, Drew J, Hofland H, Tan J. Olumacostat glasaretil, a novel topical sebum inhibitor, in the treatment of acne vulgaris: A phase IIa, multicenter, randomized, vehicle-controlled study. J Am Acad Dermatol. 2017; 76:33-39.

30. Appiah S, Lawley B, Vu M, Bell C, Jones H. Evaluation of the effectiveness of Eladi Keram for the treatment of acne vulgaris: A randomised controlled pilot study. Eur J Integr Med. 2017; 12:38-43.

31. Fox L, Csongradi C, Aucamp M, du Plessis J, Gerber M. Treatment modalities for acne. Molecules. 2016; 21:1063.

32. Tax G, Urbán E, Palotás Z, Puskás R, Kónya Z, Bíró T, Kemény L, Szabó K. Propionic acid produced by Propionibacterium acnes strains contributes to their pathogenicity. Acta Derm Venereol. 2016; 96:43-49.

33. Chessa D, Ganau G, Spiga L, Bulla A, Mazzarello V, Campus GV, Rubino S. Staphylococcus aureus and Staphylococcus epidermidis virulence strains as causative agents of persistent infections in breast implants. PLoS One. 2016; 11:e0146668.

34. Oliveira WF, Silva PMS, Silva RCS, Silva GMM, Machado G, Coelho L, Correia MTS. Staphylococcus aureus and Staphylococcus epidermidis infections on implants. J Hosp Infect. 2018; 98:111-117.

35. Khorvash F, Abdi F, Kashani HH, Naeini FF, Narimani T. Staphylococcus aureus in acne pathogenesis: A casecontrol study. N Am J Med Sci. 2012; 4:573-576. 
36. Ibberson CB. Hyaluronidase in Staphylococcus aureus physiology and pathogenesis. University of Lowa, 2015.

37. Moreno AMS. An Attempt to Elucidate the Genes Encoding the Surface Exposed Proteins R3, Z1 and Z2 in Two Strains of Streptococcus agalactiae from Zimbabwe. Norwegian University of Science and Technology, 2014.

38. Kumar B, Pathak R, Mary PB, Jha D, Sardana K, Gautam HK. New insights into acne pathogenesis: Exploring the role of acne-associated microbial populations. Dermatol Sin. 2016; 34:67-73.

39. Verkalk N, Schurink C, Melles D. Antibiotic treatment of Propionibacterium acnes endocarditis. Clin Microbiol Infect. 2018; 24:171-174.

40. Ridden J, Ferguson D, Kealey T. Organ maintenance of human sebaceous glands: in vitro effects of 13-cis retinoic acid and testosterone. J Cell Sci. 1990; 95:125136.

41. McAteer JA, Douglas WH. Monolayer culture techniques. Methods Enzymol. 1979; 58:132-140.

42. Zouboulis CC, Xia L, Akamatsu H, Seltmann H, Fritsch M, Hornemann S, Rühl R, Chen W, Nau H, Orfanos C. The human sebocyte culture model provides new insights into development and management of seborrhoea and acne. Dermatology. 1998; 196:21-31.

43. Xia L, Zouboulis C, Detmar M, Mayer-da-Silva A, Stadler R, Orfanos CE. Isolation of human sebaceous glands and cultivation of sebaceous gland-derived cells as an in vitro model. J Invest Dermatol. 1989; 93:315321.

44. Toyoda M, Morohashi M. Pathogenesis of acne. Med Electron Microsc. 2001; 34:29-40.

45. Rodriquez-Tudela J, Donnelly J, Arendrup M, Arikan S, Barchiesi F, Bille J, Chryssanthou E, Cuenca-Estrella M, Dannaoui E, Denning D. Subcommittee on Antifungal Susceptibility Testing (AFST) of the ESCMID European Committee for Antimicrobial Susceptibility Testing. EUCAST Technical Note on the method for the determination of broth dilution minimum inhibitory concentrations of antifungal agents for conidiaforming moulds. Clin Microbiol Infect. 2008; 14:982-984.

46. Hamdy A, Kassem H, Awad G, El-Kady S, Benito MT, Doyagüez E, Jimeno M, Lall N, Hussein A. In-vitro evaluation of certain Egyptian traditional medicinal plants against Propionibacterium acnes. S Afr J Bot. 2017; 109:90-95.

47. Nipanikar S, Chitlange S, Nagore D. Evaluation of anti-inflammatory and antimicrobial activity of AHPL/ AYCAP/0413 capsule. Pharmacognosy Res. 2017; 9:273-276.

48. Ye F, Imamura K, Imanishi N, Rhodes L, Uno H. Effects of topical antiandrogen and 5-alpha-reductase inhibitors on sebaceous glands in male fuzzy rats. Skin Pharmacol. 1997; 10:288-297.

49. Rubinchik E, Dugourd D, Algara T, Pasetka C, Friedland HD. Antimicrobial and antifungal activities of a novel cationic antimicrobial peptide, omiganan, in experimental skin colonisation models. Int J Antimicrob Agents. 2009; 34:457-461.

50. Xia L, Zouboulis CC, Ju Q. Culture of human sebocytes in vitro. Dermatoendocrinol. 2009; 1:92-95.

51. Thiboutot D, Gilliland K, Cong Z, Jabara S, McAllister JM, Sivarajah A, Clawson G. Human skin is a steroidogenic tissue: Steroidogenic enzymes and cofactors are expressed in epidermis, normal sebocytes, and an immortalized sebocyte cell line (SEB-1). J Invest
Dermatol. 2003; 120:905-914.

52. Zouboulis CC, Dessinioti C. Experimental Models of the Sebaceous Gland. In: Pathogenesis and Treatment of Acne and Rosacea (Zouboulis CC, Katsambas AD, Kligman AM, eds.). Springer, Berlin, Heidelberg, 2014; pp. 43-49.

53. Potter JE, Prutkin L, Wheatley VR. Sebaceous gland differentiation. I. Separation, morphology and lipogenesis of isolated cells from the mouse preputial gland tumor. J Invest Dermatol. 1979; 72:120-127.

54. Laurent SJ, Mednieks MI, Rosenfield RL. Growth of sebaceous cells in monolayer culture. In Vitro Cell Dev Biol. 1992; 28A:83-89.

55. Rosenfield RL, Deplewski D, Kentsis A, Ciletti N. Mechanisms of androgen induction of sebocyte differentiation. Dermatology. 1998; 196:43-46.

56. Wheatley VR, Potter JE, Lew G. Sebaceous gland differentiation: II. The isolation, separation and characterization of cells from the mouse preputial gland. J Invest Dermatol. 1979; 73:291-296.

57. Rosenfield RL, Kentsis A, Deplewski D, Ciletti N. Rat preputial sebocyte differentiation involves peroxisome proliferator-activated receptors. J Invest Dermatol. 1999; 112:226-232.

58. Wheatley VR, Brind JL. Sebaceous gland differentiation: III. The uses and limitations of freshly isolated mouse preputial gland cells for the in vitro study of hormone and drug action. J Invest Dermatol. 1981; 76:293-296.

59. Glasenhardt K, Erdei L, Bolla B, Tax G, Urbán E, Kemény L, Szabó K. Development of an in vitro follicle model to study the interaction of keratinocytes, sebocytes and Propionibacterium acnes. J Invest Dermatol. 2016; 136:S223.

60. Schneider MR, Paus R. Sebocytes, multifaceted epithelial cells: Lipid production and holocrine secretion. Int J Biochem Cell Biol. 2010; 42:181-185.

61. Esselin N, Capallere C, Meyrignac C, Plaza C, Coquet C, Busuttil V, Botto J, Domloge N. Generation and quantification of oxidized squalene to develop an acne testing model in vitro based on skin tissue engineering. J Invest Dermatol. 2016; 136:S173.

62. Cibula D, Hill M, Vohradnikova O, Kuzel D, Fanta M, Zivny $\mathrm{J}$. The role of androgens in determining acne severity in adult women. Br J Dermatol. 2000; 143:399404.

63. Griffiths CE, Finkel LJ, Tranfaglia MG, Hamilton TA, Voorhees JJ. An in vivo experimental model for effects of topical retinoic acid in human skin. Br J Dermatol. 1993; 129:389-394.

64. De Young LM, Young JM, Ballaron SJ, Spires DA, Puhvel SM. Intradermal injection of Propionibacterium acnes: A model of inflammation relevant to acne. J Invest Dermatol. 1984; 83:394-398.

65. Jang YH, Lee KC, Lee S-J, Kim DW, Lee WJ. HR-1 mice: A new inflammatory acne mouse model. Ann Dermatol. 2015; 27:257-264.

66. Rottboell L, de Foenss S, Thomsen K, Christiansen H, Andersen SM, Dam TN, Rosada C, Stenderup K. Exploring valrubicin's effect on Propionibacterium acnes-induced skin inflammation in vitro and in vivo. Dermatol Reports. 2015; 7:6246.

67. Tsai TH, Chuang LT, Lien TJ, Liing YR, Chen WY, Tsai PJ. Rosmarinus officinalis extract suppresses Propionibacterium acnes-induced inflammatory responses. J Med Food. 2013; 16:324-333. 
68. Bialecka A, Mak M, Biedron R, Bobek M, Kasprowicz A, Marcinkiewicz J. Different pro-inflammatory and immunogenic potentials of Propionibacterium acnes and Staphylococcus epidermidis: Implications for chronic inflammatory acne. Arch Immunol Ther Exp (Warsz). 2005; 53:79-85.

69. Ryu S, Han HM, Song PI, Armstrong CA, Park Y. Suppression of Propionibacterium acnes infection and the associated inflammatory response by the antimicrobial peptide P5 in mice. PLoS One. 2015; 10:e132619.

70. Lee WR, Kim KH, An HJ, Kim JY, Chang YC, Chung H, Park YY, Lee ML, Park KK. The protective effects of melittin on Propionibacterium acnes-induced inflammatory responses in vitro and in vivo. J Invest Dermatol. 2014; 134:1922-1930.

71. Zhang Z, Mu L, Tang J, Duan Z, Wang F, Wei L, Rong M, Lai R. A small peptide with therapeutic potential for inflammatory acne vulgaris. PLoS One. 2013; 8:e72923.

72. Kahraman E, Güngör S. Polymeric micellar nanocarriers of benzoyl peroxide as potential follicular targeting approach for acne treatment. Colloids Surf B. 2016; 146:692-699.

73. Ravi R, Senthil K, Parthiban S. Formulation and evaluation of the microsponges gel for an anti-acne agent for the treatment of acne. Indian J Pharm Sci Res. 2013; 3:32-38.

74. Vora J, Srivastava A, Modi H. Antibacterial and antioxidant strategies for acne treatment through plant extracts. Inform Med Unlock. 2018; 13:128-132.

75. Wahi AK, Singh A, Singh AK. Determination of minimum inhibitory concentration (MIC) of some novel triazole derivative. Int J Res Pharm Chem. 2011; 1:1108-1114.

76. Budhiraja A, Dhingra G. Development and characterization of a novel antiacne niosomal gel of rosmarinic acid. Drug Deliv. 2015; 22:723-730.

77. Dinant A, Boulos RA. Zolav ${ }^{\circledR}$ : A new antibiotic for the treatment of acne. Drug Des Devel Ther. 2016; 10:1235.

78. Rodríguez-Tudela JL, Barchiesi F, Bille J, Chryssanthou E, Cuenca-Estrella M, Denning D, Donnelly JP, Dupont B, Fegeler W, Moore C, Richardson M, Verweij PE. Method for the determination of minimum inhibitory concentration (MIC) by broth dilution of fermentative yeasts. Clin Microbiol Infect. 2003; 9:1-8.

79. Andrews JM. Determination of minimum inhibitory concentrations. J Antimicrob Chemother. 2001; 48:5-16.

(Received December 10, 2018; Revised December 18, 2018; Accepted December 29, 2018) 